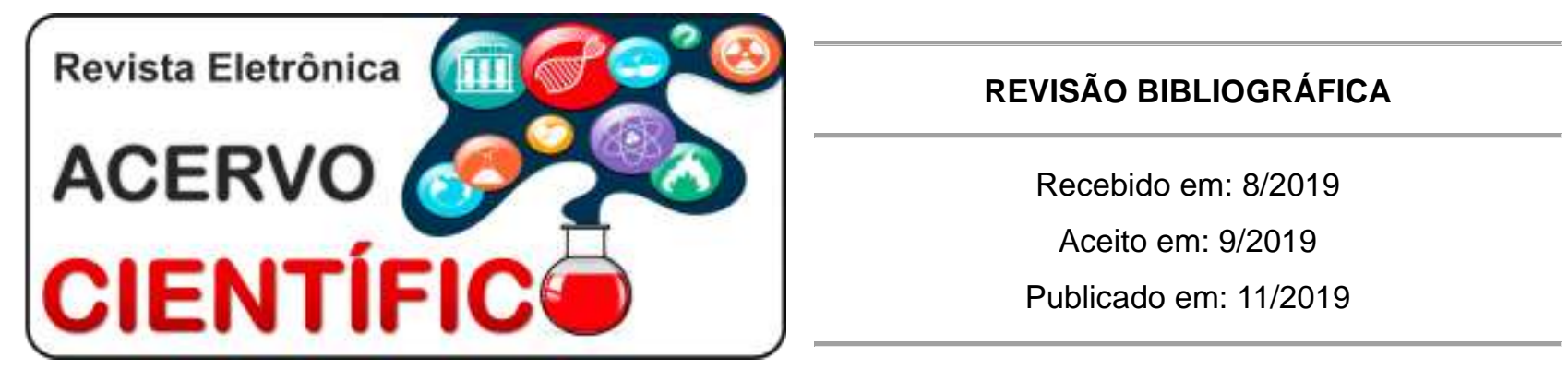

\title{
Parcerias públicas privadas em contraponto com os presídios de minas gerais e amazonas
}

\author{
Private public partnerships against the presidents of Minas Gerais and Amazonas \\ Alianzas públicas privadas contra los presidentes de Minas Gerais y Amazonas
}

Francisco Roberth da Silva Melo ${ }^{1 *}$, Rubens Alves da Silva².

\begin{abstract}
Resumo: O artigo abordou a importância da gestão compartilhada, entre o setor público e o setor privado âmbito do sistema prisional brasileiro. Foram abordados os conceitos na visão dos principais administrativistas pátrios, além das modalidades e principais características das PPP. O principal objetivo do presente trabalho consiste em identificar a utilização das Parcerias Público Privadas em contraponto com os presídios de Minas Gerais e do Amazonas com base na moderna forma de gestão pública que são as parcerias Pública-Privadas, principalmente na questão da gestão do sistema prisional, ainda contaminado pelas disfunções da Teoria da Burocracia. Concluiu-se que o processo de parceria Público Privada promove uma melhor aproximação entre o poder público e a sociedade.
\end{abstract}

Palavras-chave: Parcerias, Serviços Públicos, Concessão, Sistema Prisional.

\begin{abstract}
The article addressed the importance of shared management between the public and private sectors within the Brazilian prison system. The concepts were approached in the view of the main administrative administrators, as well as the modalities and main characteristics of the PPPs. The main objective of this work is to identify the use of Public Private Partnerships in contrast to the prisons of Minas Gerais and Amazonas based on the modern form of public management that is the Public-Private partnerships, especially in the issue of prison system management, still contaminated by the dysfunctions of Bureaucracy Theory. It was concluded that the process of public-private partnership promotes a better approximation between the public power and society.
\end{abstract}

Keywords: Partnerships, Public services, Concession, Prison system.

Resumen: El artículo abordaba la importancia de la gestión compartida entre los sectores público y privado dentro del sistema penitenciario brasileño. Los conceptos se abordaron en la opinión de los principales administradores administrativos, así como las modalidades y características principales de las APP. El objetivo principal de este trabajo es identificar el uso de las asociaciones público-privadas en contraste con las cárceles de Minas Gerais y Amazonas basadas en la forma moderna de gestión pública que son las asociaciones público-privadas, especialmente en el tema de la gestión del sistema penitenciario, todavía contaminado por las disfunciones de la teoría de la burocracia. Se concluyó que el proceso de asociación público-privada promueve una mejor aproximación entre el poder público y la sociedad.

Palabras clave: Asociaciones, Utilidad, Concesión, Sistema penitenciario.

1 Universidade Luterana do Brasil - ULBRA, Manaus-Amazonas. *E-mail: francisco.roberth2015@gmail.com

${ }^{2}$ Faculdade de Direito do Sul de Minas, Vargínia, Minas Gerais, Docência e Gestão do Ensino Superior pela Estácio, Manaus, Amazonas. 


\section{INTRODUÇÃO}

As Parcerias Públicas Privadas (PPPs) foram introduzidas no ordenamento jurídico brasileiro por meio da Lei 11.079/2004, ganhando a partir de então enorme importância na gestão de serviços públicos. Nos últimos anos, seus pressupostos básicos têm sido utilizados em alguns Estados $\mathrm{n}$ Brasil, no âmbito da administração do sistema prisional, principalmente, com o fito de solucionar vários problemas existentes. (BINENBOJM G, 2005).

Cabe ao Estado buscar soluções que amenizem a situação dos presídios, que lembram verdadeiras masmorras medievais, constituindo afronta aos direitos da pessoa humana. Nesse sentido, vê-se a possibilidade de se delegar à iniciativa privada parte desta incumbência que, em tese caberia ao Estado. (SANTOS WC, 2017).

As Parcerias Público Privadas (PPP) se consolidam a partir das premissas emanadas do Direito Administrativo para normatizar a relação entre o Estado e as empresas privadas no âmbito da gestão da gestão pública para resolver problemas em que o Estado já não consegue se impor administrativamente (LINDER SH, 1999).

Elas se originaram na Inglaterra como forma de continuar provendo serviços públicos de qualidade sem dispender investimentos que comprometiam o orçamento público e rapidamente se expandiu para outros países europeus (PASIN JAB e BORGES LFX, 2003).

Desta forma, as parcerias público privadas foram introduzidas para consolidar o papel do Estado como provedor de serviços públicos de qualidade, as denominadas Private Finance Iniciative, mas com a decisiva participação do setor privado como investidos e mantenedor dos referidos serviços se caracterizando como fundamentais manutenção de serviços públicos de qualidade (ALVARENGA JE, 2005).

Assim, com as PPPs, não podem ser caracterizadas como privatização dos serviços públicos, já que sua principal condicionalidade e a manutenção do Estado como provedor dos serviços públicos e sua principal especificidade é a operacionalização dos referidos serviços públicos pela iniciativa privada (LINDER SH, 1999).

No Brasil, a taxa de ocupação dos presídios chega a 166\%, ou seja, existe muita demanda e pouca oferta de presídios e na Região Norte do Brasil, essa taxa alcança $200 \%$, o que transforma a situação em um barril de pólvora constante. Além da superlotação dos presídios existe o problema crônico de gestão. Em alguns Estados brasileiros, já se deu início ao Processo de PPPs, na gestão dos presídios brasileiros, embora muito incipientes. No Estado de Minas Gerais, por exemplo, só existe um presídio, que se localiza na região Metropolitana de Belo Horizonte (MG) que tem provido resultados muito positivos. Em outros Estados essa relação ainda engatinha, sendo alvo de muitas críticas. No Estado do Amazonas, temos a terceirização do sistema de segurança interna que tem causado mais problemas do que soluções, mas dois novos presídios estão sendo construídos e tem-se a intenção de se realizar uma PPP na gestão, embora os investimentos na construção sejam unicamente do Estado (RODRIGUES AP, 2017).

Os benefícios das PPPs no sistema prisional são evidentes, mas a principal é uma redução de custos bem significativa, como ocorreu no presídio de Minas Gerais, cuja redução já chegou à marca de $10 \%$, o que gera sem dúvida melhoria dos padrões orçamentários do Estado. Nessa esteira, este artigo realizou uma análise comparativa entre os modelos implantados no presídio localizado no Estado de Minas Gerais e no Complexo Penitenciário, localizado no Estado do Amazonas por meio de uma pesquisa de revisão integrativa em que se comparavam os achados bibliográficos entre si (LIMA IB, 2017).

\section{REVISÃO BIBLIOGRÁFICA}

As Parcerias Público Privadas surgiram no contexto das reformas administrativas implementadas na década de 1990 no Brasil, durante o governo Fernando Henrique Cardoso (FHC) e teve como modelo, o que foi aplicado na Inglaterra de Margareth Thatcher no início dos anos 1980 . Esse momento foi marcado pelas privatizações de várias empresas estatais, com o fito de buscar a capacidade de investimento por 
parte do Estado. Ao mesmo tempo em que o Estado brasileiro procurou recuperar a sua capacidade de investimento, através das privatizações, teve que proporcionar condições mínimas para tanto, sem as quais a iniciativa privada não encamparia a ideia (LIMA CEDO, 2014).

A lei no 8.987/1995 representou grande avanço no tocante às privatizações, através da concessão e permissão de serviços públicos. Todavia, essa sistemática já não conseguia mais atrair com a mesma intensidade a iniciativa privada, em função da necessidade de investimentos vultosos que a iniciativa privada necessitava para aferir condições para que as ovas empresas privatizadas pudessem gerar lucros rapidamente. Precisava da presença do Estado, ainda que em forma de parceria (SUNDFELD CA, MONTEIRO E, ROSILHO A. 2017).

No Brasil antes de FHC chegar ao poder o modelo era de concessão que não atrais mais nenhum tipo de investidor em função dos enormes entraves burocráticos provindos do ordenamento jurídico brasileiro, além de que as principais empresas estatais brasileiras já haviam sido privatizadas, como a EMBRAER, e a vale do Rio Doce, por exemplo, o que abria poucas perspectivas para investimentos com retorno (LIMA CEDO, 2004).

Assim, para continuar um processo de prover serviços públicos de qualidade, era imprescindível que se revisse o processo das concessões em nosso modelo de administração pública, abrindo-se caminho para as PPPs. Por meio da lei o 11.079 de 30 de dezembro de 2004 introduziram-se normas gerais de licitação e contratação de Parcerias Público Privadas no Brasil (MILESK HS, 2005).

As parcerias públicas privadas são modalidades específicas de contratos de concessão, as quais teriam sido instituídas e reguladas pela lei no 11.079/2004 que trata de normas gerais, de caráter nacional, editada com fundamento na competência estabelecida no inciso XXVII do art. 22 da Constituição da República. (ALEXANDRINO M e PAULO V, 2013).

O dispositivo constitucional em questão assevera que cabe à União legislar privativamente sobre normas gerais de licitação e contratação, em todas as modalidades, para as administrações públicas diretas e indiretas, sendo a responsável, embora em regime de gestão compartilhada pelos provimentos de serviços públicos (MILESK HS, 2005).

No ordenamento jurídico brasileiro, notadamente no Direito Administrativo estão normatizadas todas as condicionalidades e especificidades da PPPs e dos contratos de concessão ainda vigentes que podem incluir ou não a realização de obra pública, especificando como tais serviços devem ser remunerados pelo Estado com a necessária contraprestação pecuniária do parceiro público (DI PIETRO MSZ, 2017).

As Parcerias Público Privadas podem ser formalizadas mediante concessão patrocinada ou administrativa, consoante previsto no art. $2^{\circ}$, parágrafos $1^{\circ}$ e $2^{\circ}$, respectivamente, da lei $\mathrm{n}^{\circ}$ 11.079/1995 (MILESK HS, 2005).

O par. 1ำ define a concessão patrocinada como sendo a concessão de serviços públicos ou de obras públicas de que trata a Lei $\mathrm{n}^{\circ}$ 8.987, de 13 de fevereiro de 1995, quando envolver, adicionalmente à tarifa cobrada dos usuários contraprestação pecuniária do parceiro público ao parceiro privado (SASSO RC, 2016).

Segue o exemplo do serviço de transporte público intramunicipal de passageiros urbanos, em que determinado município firma PPP com uma empresa do setor de transportes. Nessa modalidade de concessão, ficará avençado que paralelamente à tarifa cobrada dos usuários, a Prefeitura Municipal também fará uma contraprestação ao parceiro privado. A referida concessão patrocinada é aquela utilizada para delegação dos denominados serviços públicos "uti singuli", cabível na hipótese em que o empreendimento não é financeiramente autossustentável ou como instrumento da modicidade das tarifas. (MAZA A, 2012).

Por sua vez, o par. $2^{\circ}$ da lei ํํ 11.079/1995 define a concessão administrativa nos seguintes termos: é o contrato de prestação de serviços de que a Administração Pública seja a usuária direta ou indireta, ainda que envolva execução de obra ou fornecimento e instalação de bens. Nota-se grande diferença com relação 
à modalidade de concessão patrocinada, tendo em vista que nesta os usuários também participam da remuneração do parceiro privado, enquanto na concessão administrativa apenas a administração pública paga o parceiro privado (SASSO RC, 2016).

O parágrafo $4^{\circ}$ do art. $2^{\circ}$ da lei $n^{\circ} 11.079 / 2004$ veda o uso de PPP para prestação de serviços que durem menos de cinco ou mais de trinta e cinco anos. Veda-se também a celebração de PPP para contratos cujo valor seja inferior a 10 milhões de reais (SASSO RC, 2016).

Em Minas Gerais, o governo mineiro celebrou contrato de concessão, por meio de PPP, com a empresa GPA S/A. O contrato firmado versa sobre a construção e gestão do Complexo Penitenciário localizado no município mineiro de Ribeirão das Neves. O contrato inclui a prestação de serviços de saúde de baixa complexidade, o fornecimento de educação básica e média os internos que dela necessitarem, além de desenvolvimento técnico-operacional em educação profissional. Também consta no contrato a necessidade da presença de um médico, de um psicólogo e de enfermeiros no local, ale de prover serviços de lazer e esportes (SILVA AF, 2018).

A forma de desembolso pelos serviços prestados está atrelada ao cumprimento de metas que foram definidas em contrato, além de conter uma especificidade bem plausível: a disponibilidade de vagas no presídio. Outras condicionalidades estão atreladas a melhoria dos indicadores de qualidade como a redução do número de fugas, a inexistência de rebeliões e/ou motins, ao aumento do nível de escolaridade dos internos, a produtividade dos mesmos em relação ao trabalho exercido na prisão, o nível de saúde dos internos e os avanços na assistência jurídica e psicológica. O contrato tem duração de 27 anos com investimento da ordem de 2 bilhões de reais (SILVA AF, 2018).

Os resultados são promissores neste presídio comparados aos outros presididos mineiros, em que a PPP não existe, e sim um processo de terceirização da gestão. Onde está instalada a PPP não existe fuga, não existem motins e nem rebeliões. O presídio não está superlotado; as condições de saúde dos presos são consideradas boas; a assistência jurídica, psicológica e médica em geral, é muito condizente com a realidade de presídios europeus, por exemplo; e, o nível de satisfação dos presos com a possibilidade de ressocialização é muito grande (SILVA AF, 2018).

No Estado do Amazonas não há processo de PPP. O contrato foi realizado sob o regime de execução por preço global. Funcionando, desde o final de 2003, o sistema de terceirização operacional em Manaus, é o resultado de uma parceria entre o Estado do Amazonas, através da Secretaria de Justiça, Cidadania e Direitos Humanos - SEJUS e empresas de Administração Prisional que vem sendo substituídas de acordo com quem está ocupando o poder central do Estado. De acordo com o item II, da cláusula quarta do contrato de gestão atual, "é da competência da contratada: selecionar, recrutar, contratar sob sua inteira responsabilidade, observadas as regras de seleção, os recursos humanos necessários para o pleno desenvolvimento dos estabelecimentos prisionais, assumindo os encargos administrativos dos mesmos, e cumprindo com todas as obrigações trabalhistas, fiscais, previdenciárias e outras, em decorrência de sua condição de empregadora/contratante" (LIMA IB, 2017).

É um modelo diferente do modelo mineiro (embora em um único presídio), em função, principalmente da forma de remuneração que no Amazonas não está atrelado ao cumprimento de metas, o que descaracteriza qualquer forma de contrato que seja estabelecido (concessão, terceirização e/ou PPP) (LIMA IB, 2017).

O art. $6^{\circ}$ da lei $n^{\circ}$ 11.079/2004 dispõe no parágrafo $1^{\circ}$ que: "O contrato poderá prever o pagamento ao parceiro privado de remuneração variável vinculada ao seu desempenho, conforme metas e padrões de qualidade e disponibilidade definidos no contrato", o que não ocorre no Estado do Amazonas e por isso não pode ser considerado uma PPP (MILESK HS, 2005).

Na celebração de Parceria Público Privada numa área tão importante e sensível como é o caso do sistema prisional brasileiro é imprescindível à fixação de metas, sob pena de não se atingir os resultados almejados. Da análise dos termos do contrato firmado entre o Estado e a empresa privada gerenciadora dos estabelecimentos, conclui-se que ao primeiro remanesce a indelegável função de acompanhar a aplicação da pena, fazer a progressão dos regimes fechado para o semiaberto, e deste para o aberto. Nas palavras 
de um Magistrado ligado à execução penal da Comarca de Manaus, publicada no Jornal Diário do Amazonas, de 25/10/2012: "nossa penitenciária é terceirizada. Então, essa questão de limpeza, alimentação e outros serviços que englobam a chamada atividade-meio, é uma empresa que cuida. A parte referente à administração da pena, à execução mesma da pena, é da nossa competência" (NAVEGANTE AMQ, 2017).

Mas o problema do gerenciamento prisional adotado apresenta ineficiência sob o aspecto da corrupção e do tráfico de drogas entre os presos, pois conforme um documento da SEJUS: "O tráfico de drogas e a corrupção de agentes de segurança ainda é muito forte nos presídios, por mais que para se evitar a intimidade dos internos com os agentes de disciplina é realizado um rodízio de funcionários por hora e setor, já que qualquer suspeita de intimidade do agente de disciplina com os internos, aquele (o agente) é desligado, para não se deixar nenhuma suspeita o que denota uma preocupação central com a questão". (NAVEGANTE AMQ, 2017).

Todos os componentes dos indicadores que são utilizados no presídio onde está instalada a PPP em Minas Gerais, são constantes da Lei de Execuções Penais - LEP e estão contidas no contrato de concessão do governo do Estado do Amazonas com a empresa terceirizada, mas não há, no mesmo, a aplicação de remuneração de acordo com metas de qualificação como no presídio mineiro o que demora apenas uma transferências de atividades e não o compartilhamento de responsabilidade cerne das PPPs.

\section{CONSIDERAÇÕES FINAIS}

As Parcerias Público Privadas constituem importante instrumento de atração de investimentos privados para a concretização de diversos direitos sociais, entre os quais os direitos assegurados na Constituição da República àqueles que cumprem penas. Tendo em vista o atual contexto de crise no sistema penitenciário brasileiro, a busca de parcerias junto ao setor privado tem se mostrado importante alternativa na busca de melhorias deste combalido sistema, não obstante a crítica de alguns estudiosos do assunto. Verificou-se, assim, que existe diferença enorme entre a PPP aplicada em um presídio em Minas Gerais e o proceso de terceirização e/ou concessão dos serviços no Amazonas estão diretamente ligadas às questões de remuneratórias: Em Minas Gerais, a remuneração está ligada ao cumprimento de metas. Já no Amazonas, não, na vez que a remuneração é por preço global, sem nenhuma necessidade de cumprimento de metas.

\section{AGRADECIMENTOS E FINANCIAMENTO}

Agradeço ao Centro Universitário Luterano de Manaus/ULBRA pela possibilidade de realizar um curso de imensa qualidade, com a presença de profissionais de muita qualidade, bem como pelo fornecimento de toda a infraestrutura para a realização da pesquisa.

\section{REFERÊNCIAS}

1. AleXANDRINO M, PAULO V. Direito Administrativo Descomplicado/ Marcelo Alexandrino, Vicente Paulo. 21 ed. ver. e atual. Rio de Janeiro: Forense; São Paulo: Método, 2013.

2. AMAZONAS. Documento de avaliação da terceirização dos presídios. Manaus: SEJUS, 2017.

3. BINENBOJM G. As parcerias público-privadas (PPPs) e a Constituição. R. Dir. Adm., Rio de Janeiro, 241: 159175, Jul/set. 2005.

4. BRASIL. Constituição da República Federativa do Brasil. Brasília: Congresso nacional, 1988. Disponível em http://senadofederal.gov.br Acesso em 15 de out de 2019.

5. BRASIL. Lei de Execução Penal - Lei no 7.210, de 11 de julho de 1984. Institui a Lei de Execução Penal. Vademecum Universitário de Direito. São Paulo: Jurídica brasileira, 2001.

6. DI PIETRO MSZ. Direito Administrativo/Maria Sylvia Zanella Di Pietro. 30 ed. Rio de Janeiro: Forense, 2017.

7. JORNAL DIÁRIO DO AMAZONAS. Caderno cidade. 25/10/2012.

8. LIMA CEDO. A instituição das Parcerias Público-privadas e sua aplicação na Administração Pública brasileira. Revista Jus Navigandi. ISSN 1518-4862, Teresina, ano 19, n. 3925, 31 mar. 2014. Disponível em: https://jus.com.br/artigos/27175. Acesso em: 15 de agosto de 2019. 
9. LIMA IB. Prisão-Negócio: Terceirização do Sistema Penitenciário e Pesquisa com Agentes de Disciplina/Socialização na Onda Punitiva do Amazonas. Doutorando do Programa de Pós-graduação em Sociologia da Universidade Federal do Ceará. Revista Elaborar Vol. 4, ano 5, n.2, 2017, ISSN 2318-993235

10. MILESKI HS. Parcerias Público-Privadas: fundamentos, aplicação e alcance da lei, elementos definidores, princípios, regras específicas para licitações e contratos, aspectos controvertidos, controle e perspectivas de aplicação da Lei no 11.079 de 30.12.2004. Publicado na revista INTERESSE PÚBLICO. - Ano 6, no 29, janeiro/fevereiro/2005 - Porto Alegre: Notadez.

11. NAVEGANTE AMQ. Terceirização dos serviços de segurança interno dos presídios na cidade de Manaus. Trabalho apresentado como nota da Disciplina Monografia II, solicitada pelo professor Fábio Monteiro, do Instituto de Ensino Superior da Amazônia - IESA, Faculdade Martha Falcão, como pré-requisito para a graduação de Bacharel em Direito e requisito obrigatório da 1ํㅡ NPC do Curso de Graduação em Direito sob a orientação de Dorli João Carlos Marques (professor da disciplina monografia) e Carlos Fábio Braga Monteiro (professor orientador), 2016.

12. PASIN JAB, BORGES LFX. A nova definição de parceria público-privada e sua aplicabilidade na gestão de infraestrutura pública. Revista do BNDES. Rio de Janeiro, v. 10, N. 20, P. 173-196, dez. 2003.

13. SANTOS WC. Parceria Público-Privada no Sistema Penitenciário Brasileiro. Monografia apresentada como requisito parcial para conclusão do curso de Bacharel em Direito da Faculdade de Ciências Jurídicas e Sociais do Centro Universitário de Brasília. Orientador: Prof. Gabriel Haddad Teixeira, Brasília, 2017. Versão digitalizada.

14. SASSO RC. A constitucionalidade e a conveniência da concessão administrativa criada pela Lei nº 11.079/2004 para a máxima efetivação do direito fundamental à saúde. Dissertação apresentada ao Programa de PósGraduação em Direito da Faculdade de Direito de Ribeirão Preto da Universidade de São Paulo para obtenção do título de Mestre em Ciências. Versão Corrigida. A original encontra-se disponível na Biblioteca da FDRP/USP. Área de Concentração: Desenvolvimento no Estado Democrático de Direito. Orientador: Prof. Dr. Gustavo Assed Ferreira, Ribeirão Preto, 2016. Versão digitalizada.

15. SILVA AF. Análise da terceirização do sistema prisional de Minas Gerais. Projeto de monografia apresentada para obtenção de créditos para a disciplina de Monografia do curso de especialização em gestão pública da Universidade Federal de São João Del Rei. Orientador: Prof. Dr. Eduardo Sergio da Silva, ARAXÁ, 2018. Versão digitalizada.

16. SUNDFELD CA, MONTEIRO V, ROSILHO A. A estruturação das concessões por meio de parceria com particulares autorizados (art. 21 da Lei no 8.987/1995). RDA - Revista de Direito Administrativo, Rio de Janeiro, v. 275, p. 41-66, maio/ago. 2017. 